\title{
Germinal defects of SDHx genes in patients with isolated pituitary adenoma
}

\author{
Grégory Mougel ${ }^{1}$, Arnaud Lagarde ${ }^{1}$, Frédérique Albarel ${ }^{2}{ }^{2}$, Wassim Essamet ${ }^{3}$, Perrine Luigi ${ }^{4}$, Céline Mouly ${ }^{5}$, \\ Magaly Vialon ${ }^{5}$, Thomas Cuny ${ }^{6}$, Frédéric Castinetti ${ }^{6}$, Alexandru Saveanu ${ }^{1}$, Thierry Brue ${ }^{6}$, Anne Barlier ${ }^{1}$ and \\ Pauline Romanet ${ }^{1}$
}

1'Aix Marseille Univ, APHM, INSERM, MMG, Hospital La Conception, Laboratory of Molecular Biology, Marseille, France, ${ }^{2}$ Department of Endocrinology, Hospital La Conception, APHM, Marseille, France, ${ }^{3}$ Department of Pathology, Hospital La Timone, APHM, Marseille, France, ${ }^{4}$ Department of Endocrinology, Hospital Lapeyronie, CHU Montpellier, Montpellier, France, ${ }^{5}$ Department of Endocrinology, Hospital Larrey, CHU Toulouse, Toulouse, France, and ${ }^{6}$ Aix Marseille University, APHM, INSERM, MMG, Hospital La Conception, Department of Endocrinology, Marseille, France

Correspondence should be addressed to P Romanet

Email

pauline.romanet@ap-hm.fr

\begin{abstract}
Background: The '3PAs' syndrome, associating pituitary adenoma (PA) and pheochromocytoma/paraganglioma (PPGL), is sometimes associated with mutations in PPGL-predisposing genes, such as SDHx or MAX. In '3PAs' syndrome, PAs can occur before PPGL, suggesting a new gateway into SDHX/MAX-related diseases.

Objective: To determine the SDHX/MAX mutation prevalence in patients with isolated PAs and characterize PAs of patients with $S D H X / M A X$ mutations.

Design: Genes involved in PAs (AIP/MEN1/CDKN1B) or PPGLS (SDHX/MAX) were sequenced in patients with isolated PAs. We then conducted a review of cases of PA in the setting of '3PAs' syndrome.

Results: A total of 263 patients were recruited. Seven (likely) pathogenic variants were found in AIP, two in MEN1, two in $S D H A$, and one in SDHC. The prevalence of SDHx mutations reached 1.1\% (3/263). Of 31 reported patients with PAs harboring SDHX/MAX mutations (28 published cases and 3 cases reported here), 6/31 (19\%) developed PA before PPGL and 8/31 (26\%) had isolated PA. The age of onset was later than in patients with AIP/MEN1 mutations. PAs were mainly macroprolactinomas and showed intracytoplasmic vacuoles seen on histopathology.

Conclusions: We discovered SDHx mutations in patients bearing PA who had no familial or personal history of PPGL. However, the question of incidental association remains unresolved and data to determine the benefit of SDHX/MAX screening in these patients are lacking. We recommend that patients with isolated PA should be carefully examined for a family history of PPGLs. A family history of PPGL, as well as the presence of intracytoplasmic vacuoles in PA, requires SDHX/MAX genetic testing of patients.
\end{abstract}

\section{Introduction}

Although pituitary adenomas (PAs) are benign tumors, they can be responsible for clinical features due to hormonal disturbances and symptoms of compression that are secondary to local invasion and that may lead to hypopituitarism. The reported prevalence of symptomatic PAs is as high as 1 in 1000 (1). PAs are most frequently sporadic diseases, but are inherited in approximately $5 \%$ of cases. In these cases, PAs may be isolated, as in familial isolated pituitary adenomas (FIPAs) due to AIP mutation (AIP; OMIM 605555), or occur in a syndromic association, such as (1) multiple endocrine neoplasia 1 (MEN1; OMIM 131100), which predisposes patients mainly to primary hyperparathyroidism, endocrine duodeno-pancreatic tumors, and PA; and more rarely, (2) multiple endocrine https://eje.bioscientifica.com https://doi.org/10.1530/EJE-20-0054 (c) 2020 European Society of Endocrinology Printed in Great Britain
Published by Bioscientifica Ltd. 
neoplasia 4 (MEN4; OMIM 610755), which represents a MEN1-like syndrome; or (3) Carney complex (CNC; OMIM 160980) which has cutaneous manifestations, acromegaly, Cushing syndrome, myxoma and schwannoma (2). In syndromic forms or familial cases, patients may benefit from genetic screening to propose specific monitoring and genetic counseling.

Pheochromocytomas are neuroendocrine tumors arising from adrenal medulla cells. Paragangliomas originate from sympathetic or parasympathetic ganglia. The release of catecholamines by pheochromocytoma/ paraganglioma (PPGL) can lead to episodes of hypertension, profuse sweating, headaches, panic attacks, arrhythmia, stroke, and death. The standard treatment is resection and management of PPGL requires highly specialized teams. Around $40 \%$ of PPGL are genetically determined (3). Among the 20 or so predisposing genes that have been identified, some lead to a syndromic form of the disease ( $V H L, N F 1, R E T, F H$ ), while some lead to isolated forms (including $S D H D, S D H C, S D H B$, SDHA, SDHAF2, MAX, SLC25A11, TMEM127). Germinal mutations are found in $S D H x$ genes ( $S D H D, S D H C, S D H B$, $S D H A$ and SDHAF2), encoding for the SDH subunits in half of the hereditary cases.

The association between PA and PPGL was first described by Iversen in 1952 (4). This association can occur during MEN1 syndrome or independently (5, $6,7,8,9)$. This condition, called '3PAs' syndrome (for pituitary adenoma/pheochromocytoma/paraganglioma association) by Xekouki, can be described as the co-occurrence of PA and PPGL without other features of MEN1 syndrome $(5,6,10)$. This association is rare, with fewer than 100 cases published in 2019. The '3PAs' syndrome may be associated with germline mutations in genes responsible for predisposition to non-syndromic PPGL, such as genes encoding for SDH subunits or MAX $(6,7,8,9)$.

The objective of this study was to assess the involvement of the main non-syndromic PPGLpredisposing genes in patients with isolated PAs and to study the PA characteristics of patients with $S D H x / M A X$ mutations. To this end (1), we determined the prevalence of germline mutations in MEN1,CDKN1B, and AIP and in SDHA, SDHB, SDHC, SDHD, SDHAF2 (herein called $S D H x$ genes) and $M A X$ in a large series of patients for which genetic testing was performed for sporadic or familial isolated PA (2). We reviewed the literature for published cases of PA in the setting of '3PAs' syndrome to determine if patients with PA and genetic mutations in PPGL-predisposing genes show phenotypic differences compared to patients with AIP, MEN1, PRKAR1A, or $C D K N 1 B$ mutation and those with non-genetically determined PAs.

\section{Patients and methods}

\section{Subjects}

All patients who underwent genetic testing in the context of an isolated PA, without other endocrine lesions, at the molecular laboratory of Marseille Conception Hospital between November 2016 and December 2018 were included. Written informed consent from all patients for genetic analysis was obtained during one-on-one genetic counseling. This study was approved by the ethics committee of Aix-Marseille University (approval number: 2018-13-12-004).

\section{Next-generation sequencing (NGS)}

Genomic DNA was extracted from blood lymphocytes (standard EDTA samples) using QiaSymphony DS DNA Midi Kit (Qiagen). Exons and 20 bp flanking introns of AIP (NM_003977.2), MEN1 (NM_130799.2), CDKN1B (NM_004064), SDHA (NM_004168.2), SDHB (NM_003000.2), SDHC (NM_003001.3), SDHD (NM_003002.2), SDHAF2 (NM-017841.1) and MAX (NM_002382.3) were sequenced by next-generation sequencing (NGS) using the QiaSeq library (Qiagen) according to the manufacturer's instructions. This library included unique molecular indices that are added to each DNA fragment before amplification, in order to reduce the sequencing error rates and to suppress PCR duplicates. Libraries were sequenced on MiSeqDX (Illumina). The alignment and variant calling were performed using the Biomedical Genomics Workbench 5.0.1 (Qiagen) and based on human genome GRCh37/hg19. Annotation was done using VariantStudio v2.2 (Illumina), according to the HGVS guidelines (11). All regions were sequenced with coverage of depth superior to $30 \times$ after removing PCR duplicates.

We then performed copy number variation (CNV) analysis using the CNV detection tools from the Biomedical Genomics Workbench, based on the relative depth of coverage of specimen.

Each variant was classified according to the guidelines of the American College of Medical Genetics and Genomics (ACMG) into one of the five following classes (12):

Class 1: benign variant (BV)

Class 2: likely benign variant (LBV) 
Class 3: variant of uncertain significance (VUS)

Class 4: likely pathogenic variant (LPV)

Class 5: pathogenic variant (PV)

In silico predictions were performed using Alamut Visual software (Interactive Biosoftware, Rouen, France), including the conservation level, SIFT, PolyPhen-2, and the study of the splicing impact. The population data from population database (gnomAD database, https:// gnomad.broadinstitute.org/, last visited November 2019) and from inherited disease databases, ClinVar, LOVD, and HGMD, were collected. Variants with a frequency greater than 5\% in the population were not retained. All PVs and LPVs were confirmed by Sanger sequencing (primers and protocols are available upon request).

\section{Exploration of SDHx mutations in pituitary adenomas}

To examine the role of the $S D H x$ germinal mutation in PAs, both SDHB immunohistochemistry (IHC) and research of loss of heterozygosity ( $\mathrm{LOH}$ ) were performed on formalinfixed paraffin-embedded (FFPE) slides obtained from surgically removed samples of the pituitary adenoma, where this was available.

\section{SDHB IHC analysis}

The investigation of the loss of SDH complex expression in neoplastic cells was performed using a commercially available polyclonal antibody against SDHB (Sigma Aldrich, HPA002868) at a dilution of 1:150. If any component of the SDH complex is damaged, the entire SDH complex becomes unstable, releasing the SDHB subunit into the cytoplasm where it is rapidly degraded (13). The staining protocol used (XT UltraView DAB v3, Benchmark IHC/ ISH module) included pre-treatment with cell conditioner 1 , incubation with primary antibody at $37^{\circ} \mathrm{C}$, followed by incubation with Prep Kit 517 solution for $32 \mathrm{~min}$, followed by counterstaining with hematoxylin for $8 \mathrm{~min}$.

\section{Sanger sequencing for examination of $\mathrm{LOH}$ in tumors}

DNA was extracted from samples using QIAamp DNA FFPE tissue kit (Qiagen). Using the AmpliTaq Gold 360 Master Mix (ThermoFisher Scientific), DNA was amplified by PCR targeting exon 5 of SDHC or exon 13 of SDHA (primers available upon request). After purification, the PCR products were sequenced using the Sanger method on a AB3500XLDX genetic analyser (ThermoFisher Scientific).

\section{Comparison of patients with '3PAs' syndrome and 'non-3PAs' syndrome based on published data}

The characteristics of patients who presented with PA and $S D H x / M A X$ (likely) pathogenic variants were compared to patients with AIP, MEN1, PRKAR1A, CDKN1B-related PA and to patients with non-genetically determined PAs. The patients with non-genetically determined PAs came from the cohort reported by Daly et al. from a Belgian population (1). The AIP cases corresponded to 64 published cases with that phenotype (a list of references is available upon request). The MEN1 cases were extracted from the UMDMEN1 Database (14), the Carney complex cases were from a literature review published by Cuny et al. (15), and the MEN4 cases were from reviews conducted by Alrezk $e t$ al. and Fredericksen et al. $(16,17)$.

\section{Statistical analysis}

Statistical analyses were performed using Prism v6.0 (GraphPad Software). Patient characteristics were compared using the two-tailed Fisher's exact test for qualitative variables and the non-paired, non-parametric Mann-Whitney $U$-test for quantitative values.

\section{Results}

A total of 263 patients were included (Table 1 and Supplementary Table 1 , see section on supplementary materials given at the end of this article). The mean age at diagnosis of PA was 29.3 years (min: 8; max: 78), and the mean age at genetic screening was 36.1 years (min: 8; max: 79). The occurrence of PA was sporadic in 227 patients (86.3\%), while 36 patients presented with a familial history of PA (13.7\%). By NGS sequencing, we found 295 single nucleotide variants, among which 7 variants were classified as pathogenic, 5 as likely pathogenic, and 7 as VUS (Fig. 1, Table 1 and Supplementary Tables 2, 3). We did not find CNV. Five PV and LPV were found in patients with a familial history of PA out of 36 and 7 in patients with sporadic PA out of 227 . The probability to find a (likely) pathogenic variant was higher in cases of patients with a family history of PA compared to those with no history (odds ratio: 5.069, 95\% CI: 1.69-15.79, $P=0.014$ ).

Among the sporadic cases, five mutations occurred in patients younger than 30 years $(5 / 133)$ and two occurred in patients older than 30 years. Among the 12 PVs and LPVs, we found 7 variants in AIP, 2 in MEN1, 2 in SDHA, and 1 in SDHC (Supplementary Table 2). The medical 
Table 1 Clinical characteristics of the patients included in this study.

\begin{tabular}{l}
\hline \\
\hline Number of patients $(n)$ \\
Age at diagnosis (years) mean (range) \\
Sex ratio (male/female) \\
Size of pituitary adenoma \\
Macro adenoma \\
Micro adenoma \\
NA \\
Secretion of pituitary adenoma $(n, \%)$ \\
PRL \\
GH \\
NFPA \\
ACTH \\
Mixed \\
LH/FSH \\
TSH \\
NA \\
Number of variants, all genes $(n)$ \\
VUS \\
LPV \\
PV
\end{tabular}

\begin{tabular}{c}
\multicolumn{1}{c}{ Sporadic } \\
\hline$<30$ years \\
\hline 133 \\
$22.2(9-30)$ \\
$58 \mathrm{M} / 75 \mathrm{~F}(0.77)$ \\
95 \\
15 \\
23 \\
52 \\
31 \\
8 \\
21 \\
4 \\
1 \\
1 \\
15 \\
148 \\
4 \\
0 \\
5
\end{tabular}

\begin{tabular}{|c|c|}
\hline Familial cases & Total \\
\hline 36 & 263 \\
\hline $32.3(8-77)$ & $29.3(8-78)$ \\
\hline $17 \mathrm{M} / 19 \mathrm{~F}(0.9)$ & $135 \mathrm{M} / 128 \mathrm{~F}(1.05)$ \\
\hline 22 & $187(71.1 \%)$ \\
\hline 6 & $25(9.5 \%)$ \\
\hline 8 & $51(19.4 \%)$ \\
\hline 14 & $86(32.7 \%)$ \\
\hline 5 & $72(27.4 \%)$ \\
\hline 8 & $22(8.4 \%)$ \\
\hline 2 & $26(9.9 \%)$ \\
\hline 1 & $13(4.2 \%)$ \\
\hline 0 & $5(1.9 \%)$ \\
\hline 0 & $2(0.8 \%)$ \\
\hline 6 & $37(14.1 \%)$ \\
\hline 32 & 295 \\
\hline 0 & 7 \\
\hline 3 & 5 \\
\hline 2 & 7 \\
\hline
\end{tabular}

CTH, adrenocorticotropic hormone; F, female; FSH, follicular-stimulating hormone; GH, growth hormone; LH, luteinising hormone; LPV, likely pathogenic variant; M, male; NA, not available; NFPA, non-functional pituitary adenoma; PRL, prolactin; PV, pathologic variant; TSH, thyroid-stimulating hormone; VUS, variant of uncertain significance. Macroadenoma is defined by a diameter $>10 \mathrm{~mm}$; microadenoma is defined by a diameter $<10 \mathrm{~mm}$.

histories of the patients with three SDHx mutations are described subsequently and in Table 2 .

\section{Case presentation}

Case 1

A 17-year-old previously healthy male patient presented with a recent history of severe right vision loss, clinically measured on the monoyer scale (right eye: 4/10, left eye: 10/10). MRI revealed a large $(>10 \mathrm{~mm})$ cystic pituitary mass, and his prolactin level was measured at $91 \mu \mathrm{g} / \mathrm{L}$ (reference range: $4.1-15.34 \mu \mathrm{g} / \mathrm{L}$ ). The patient underwent transsphenoidal surgical debulking because of the visual defect. The post-operative examination was without complications and demonstrated a marked improvement in vision. The post-operative prolactin secretion was measured at $104 \mu \mathrm{g} / \mathrm{L}$, probably explained by an incomplete resection. Post-operative MRI displayed postoperative reorganization without visible residue, resolved 6 months later. The histopathological examination of the resected tissue was consistent with a prolactinoma showing aggressive criteria (grade $1 \mathrm{~b}$ under the new classification) (18). No neoplastic cells demonstrated vacuolated cytoplasm. The Ki-67 labeling index was 5\%, and P53 was expressed in 10\% of cells. Cabergoline was initiated at a dose of $0.5 \mathrm{mg}$ weekly, producing prolactin normalization ( $3 \mu \mathrm{g} / \mathrm{L}$ at 3 months).

A $S D H C$ : c. $405+1 G>T$, p.(?) heterozygous pathogenic variant was demonstrated. This variant was present in the population database at a weak allele frequency (Minor Allele Frequency - MAF <0.001\%). This variant has been reported as causing the deletion of exon 5 and a shift in the reading frame (19). SDHB IHC analysis of the PA was positive (Fig. 1 and Table 2), while the search for LOH in the tumor was negative. A whole-body CT and investigation of serum and urinary catecholamines did not show signs of PPGL. The SDHC variant was present in the father, who is asymptomatic at the age of 46 . Careful examination revealed no lesions, and plasma methoxyamines were normal. Imaging exploration has not to date been carried out.

\section{Case 2}

A 42-year-old male patient, with no personal or family history of endocrine disease, consulted due to an 18-month history of erectile dysfunction and decreased libido. The primary hormonal assessment found a low testosterone level $(0.64 \mathrm{ng} / \mathrm{mL})$ and a pituitary profile showing FSH of $1.3 \mathrm{IU} / \mathrm{L}, \mathrm{LH}$ of $2.7 \mathrm{IU} / \mathrm{L}$ and prolactin of $84 \mu \mathrm{g} / \mathrm{L}$, thus supporting a central origin. Cranial MRI showed a pituitary macroadenoma with a moderate 


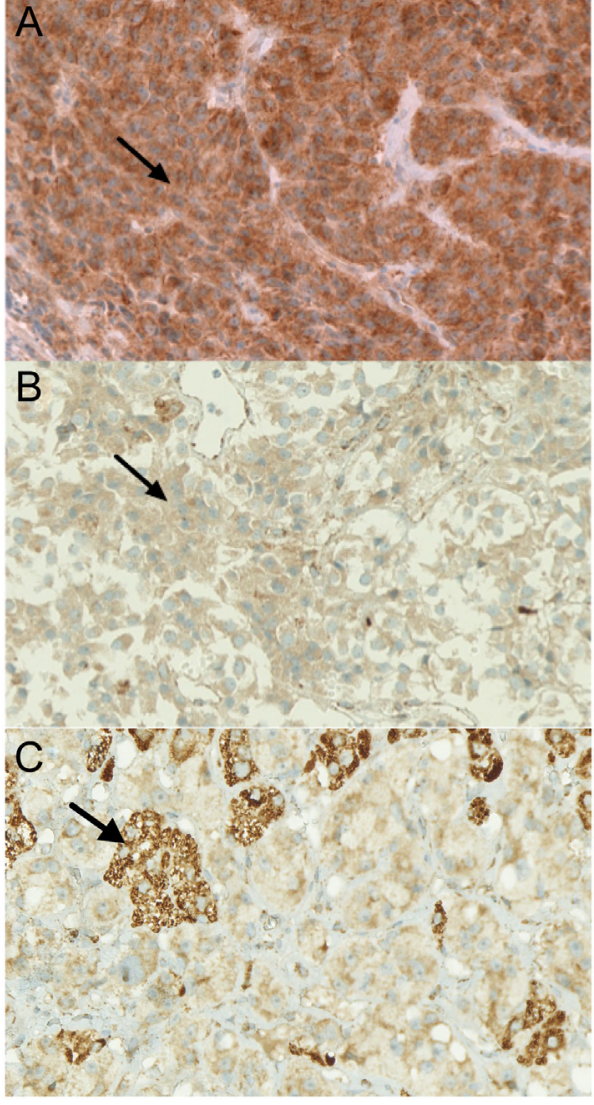

\section{Figure 1}

IHC of SDHB. (A) Pituitary adenoma of Case 1, (B) PA of Case 3, and $(C)$ pheochromocytoma. In A and B, the SDHB IHC shows a strong granular cytoplasmic staining (arrow) in tumor cells suggesting the persistence of SDH complex expression in pituitary adenomas. In C, the SDHB IHC reveals a lack of staining in pheochromocytoma tumor cells and strong granular cytoplasmic staining in clusters of cortical adrenal cells entrapped in the tumor (arrow, positive control).

suprasellar extension but no visual pathway compression. In this clinical context, cabergoline at a dose of $0.5 \mathrm{mg}$ weekly was initiated with a good medical and biological response. The analysis of $S D H A$ revealed a heterozygous frameshift variant on exon 6 of the gene (c.757_758del, p.(Val253Cys*67)), resulting in a premature stop codon. This variant was absent from gnomAD and from the FREX database, thus not reported in the French population. It was therefore classified as likely pathogenic.

\section{Case 3}

This male patient was diagnosed with an isolated microprolactinoma at 37 years of age and had a notable family history of PA, with macroprolactinoma in his family but without any history of PPGL. His brother died during surgery to remove a massive pituitary adenoma. Prolactin secretion was well-controlled under cabergoline (PRL $<10$ $\mu \mathrm{g} / \mathrm{L}$ ), but due to side effects a change to treatment with bromocriptine was made. Subsequently, prolactin levels were poorly controlled due to poor adherence to therapy (16.6 to $40 \mu \mathrm{g} / \mathrm{L}$ ). Neurosurgical removal was performed and histopathological analysis of the tumor did not show cytoplasmic vacuolization. Analysis of PPGL genes found a heterozygous missense variant in exon 13 of SDHA (c.1753C > T, p.(Arg585Trp)). This variant is present in the population database (gnomAD MAF: 0.0025\%); however, in silico analysis predicted a deleterious impact and studies have reported this variant as pathogenic (20). Therefore, this variant was classified as likely pathogenic. SDHB IHC analysis was positive (Fig. 1 and Table 1), and the search for $\mathrm{LOH}$ by Sanger sequencing was negative. Family members were not available to allow a genetic family survey to be conducted.

\section{Literature review and phenotypic features in '3PAs' syndrome}

After reclassification of the variants using ACMG criteria (12) and excluding patients with VUS or (likely) benign variants, we found 23 published cases of '3PAs' syndrome with SDHx or MAX (likely) pathogenic variants (Supplementary Table 4) (5, 6, 7, 8, 9, 21, 22, 23, 24, 25, $26,27,28,29)$. Among the 23 cases, 19 patients had $S D H x$ (likely) pathogenic variants: 2 in SDHA, 9 in $S D H B$ (39\%, 9/23), 2 in SDHC, and 6 in SDHD (26\%, 6/23); four patients had MAX pathogenic variants. PA occurred before PPGL in six cases $(6 / 23,26 \%)$. Moreover, we also found five published cases with an isolated PA and a mutation in $S D H x$ (one in $S D H A$ and four in $S D H B$ ); all of these had a family history of PPGLs (Supplementary Table 5) $(6,30$, 31, 32).

Overall, the SDHx/MAX patients with PA included those harboring PPGL ( $n=23$, Supplementary Table 4$)$, those with a family history of PPGL $(n=5$, Supplementary Table 5), and those without PPGL context ( $n=3$ from this study). Of these $31 S D H x / M A X$ patients, 6 had a family history of PA (Supplementary Table 4 and our case \#3), and among these only one without PPGL history (our case \#3). Cases included 16 females and 14 males (sex ratio: $1.1 / 1$, the sex was not specified for one patient). Diagnosis of PA was on average at 42.4 years of age (range: 16( $\min )$ - 72 ( $\max )$ years). There were 23 macroPAs, representing $74 \%$ of cases and 4 microPAs $(13 \%)$. The 
Table 2 Characteristics of patients harboring an isolated pituitary adenoma and SDHX/MAX likely pathogenic or pathogenic variants in this study: genetic exploration and functional analysis.

\begin{tabular}{|c|c|c|c|}
\hline Characteristics & Case 1 & Case 2 & Case 3 \\
\hline Sex & $\mathrm{M}$ & $\bar{M}$ & $\mathrm{M}$ \\
\hline Age at PA diagnosis & 17 & 42 & 37 \\
\hline Size of PA & Macro & Macro & Micro \\
\hline Secretion of PA & PRL & PRL & PRL \\
\hline Familial PA & No & No & $\begin{array}{l}\text { Father and brother: macroPRL } \\
\text { nephew: microPRL }\end{array}$ \\
\hline Familial PPGL & No & No & No \\
\hline PRL at diagnosis ( $\mu \mathrm{g} / \mathrm{L})$ & 91 & 84 & 55 \\
\hline Medical treatment & Cabergoline (postoperative) & Carbergoline & Cabergoline, bromocriptine \\
\hline Surgery & Yes & No & Yes \\
\hline $\begin{array}{l}\text { Results of AIP, MEN1, CDKN1B } \\
\text { genetic testing }\end{array}$ & Normal & Normal & Normal \\
\hline Gene & $S D H C$ & $S D H A$ & $S D H A$ \\
\hline Variant & c. $405+1 G>T$, p.(?) & c.757_758del, p.(Val253Cys*67) & c.1753C > T, p.(Arg585Trp) \\
\hline Classification* & PV & LPV & LPV \\
\hline Histopathological examination & Yes & No & Yes \\
\hline Hormonal status & $\mathrm{PRL}+$ & & $\mathrm{PRL}+$ \\
\hline ki67 & $5 \%$ & & $<1 \%$ \\
\hline$\%$ of P53-positive cells & $10 \%$ & & $<1 \%$ \\
\hline $\mathrm{IHC} \mathrm{SDH}$ & Positive & - & Positive \\
\hline $\mathrm{LOH}$ & Negative & - & Negative \\
\hline
\end{tabular}

Htz, heterozygous; LOH, Loss of heterozygosity; LPV, likely pathogenic variant; M, Male; macro, macroadenoma, defined by a diameter >10 mm; micro, microadenoma, defined by a diameter $<10 \mathrm{~mm}$; PRL, prolactin; PV, pathogenic variant; SDHB IHC, SDHB immunohistochemistry. ${ }^{*}$ Classification using ACMG guidelines for classification of sequence variants (12).

most frequent types were prolactinoma $(19 / 31,61 \%)$, GH-secreting adenoma and NFPA (5/31, 16\% for both) (Supplementary Table 6).

Next, we compared these SDHx/MAX patients with those from published cases of genetically determined PAs (i.e. due to mutations in AIP, MEN1, CDKN1B or $P R K A R 1 A)$ and non-genetically determined PAs. The age of occurrence of PAs in the SDHx/MAX patients (mean: 42.4 years, range: 16-72) was later than that for $A I P$ patients (mean: 25.9 years, range: 10-60, $P<0.001$ ), or MEN1 patients (mean: 34.2 years, range: $7-82, P=0.024$ ), or PRKAR1A patients (mean 31 years, range: 16-55, $P=0.007$ ) (Fig. 2 and Supplementary Table 6).

The proportion of prolactinomas was identical in $S D H x / M A X$ patients and in the control population from the cohort published by Daly et al. (66\% vs 61\%) (Supplementary Table 6) (1). However, the PAs of the 31 SDHx/MAX patients were larger (23/31 macroadenomas vs $29 / 68$ in control population $P=0.002)$. In fact, macroprolactinomas were more frequent in the $S D H x /$ $M A X$ population $(15 / 31$ vs $11 / 68 P=0.0013)$. The $S D H x /$ $M A X$ patients also presented a tendency to show an older age at PA diagnosis than in the control population (42.4 years vs 34.5 years) though this was not statistically significant $(P=0.08)$.

\section{Discussion}

Though mutations in MEN1, AIP, CDKN1B, and PRKAR1A genes have been identified as causal factors in familial PA, in most cases, no genetic cause was identified. For example, AIP mutations were found in only $20 \%$ of FIPA cases (33). In France, according to the TENgen guidelines (Oncogenetic Network in Neuroendocrine Tumors), mutations in AIP, MEN1, and CDKN1B genes are investigated in patients with PA who have (1) familial presentation, (2) syndromic association, or (3) isolated and sporadic pituitary macroadenoma occurring before the age of 30. PRKAR1A is investigated only in those patients with a typical syndromic association. Of note, in our cohort, several patients aged older than 30 years, with sporadic and isolated PA, had genetic testing on the express request of the endocrinologist due to notably aggressive or drug-resistant PAs, which are features of MEN1- and AIP-related PAs. In our cohort, the prevalence of mutations in AIP and MEN1 was consistent with the prevalence reported in the literature for patients with PAs and using similar inclusion criteria (AIP: 1.1-11.7\%, MEN1: 0-3.4\%) $(34,35,36,37,38,39)$.

Recently, a novel syndromic association termed '3PAs' and involving PAs and PPGLs has been described in some 


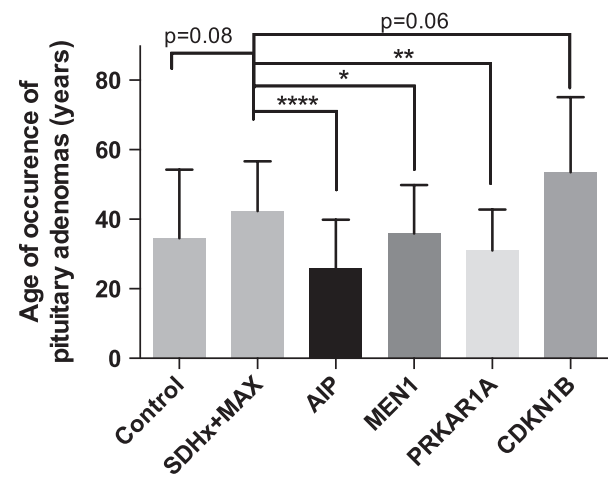

\section{Figure 2}

Comparison of age of occurrence of PAs in genetic syndromes and control patients. Control, patients with non-genetically determined PAs were selected as a reference from the patients described by Daly et al. from a Belgian population (1); AIP cases, 57 published cases (list available upon request); MEN1, MEN1 cases harboring pathogenic or likely pathogenic variants extracted from the UMD-MEN1 Database (14);

PRKAR1A, Carney complex published cases listed by Cuny et al.; $C D K N 1 B, 11$ MEN4 cases listed in reviews by Alrezk et al. and Fredericksen et al. $(16,17) .{ }^{*} P<0.05, * * P<0.01$, $\star * * * P<0.0001$.

cases associated with germline mutations in SDHx/MAX genes $(5,6,7,9,22)$. A literature review on patients with SDHX/MAX mutations showing '3PAs' syndrome found six patients in whom the PAs were present in patients with PPGLs, while five patients had an isolated PA (Supplementary Tables 4 and 5), suggesting a new gateway into $S D H x / M A X$-related diseases. These data raise several issues regarding: (1) the incidence of $S D H x / M A X$ mutations in patients with isolated PAs, (2) the characteristics of patients with isolated PAs harboring these mutations and, consequently, (3) whether mutations in SDHx/MAX genes might be looked for in patients with isolated PAs.

Herein, we highlight for the first time the co-occurrence of SDHx germline mutations in patients with an isolated PA and without personal or familial history of PPGL. In our study, among 263 patients with isolated PAs, we found 3 (likely) pathogenic variants in SDHx genes: 2 in sporadic cases of PA and 1 in a patient with a strong family history of PAs. The prevalence rate of mutations was $1.1 \%$. In 2015, Xekouki et al. studied the prevalence of $S D H x$ germline mutations in a cohort of 168 patients with PA, including 143 patients with isolated and sporadic PAs, 3 patients with sporadic '3PAs' syndrome, and 22 patients with familial '3PAs' syndrome (5). Three SDHx mutations were identified in patients with familial '3PAs' syndrome.
No mutations were found in the patients presenting with isolated PAs, probably because the cohort included a high proportion of patients with ACTH-secreting PAs $(118 / 168,70 \%)$.

It should be noted that the presence of SDHx (likely) pathogenic variants in patients with PAs might also be due to a fortuitous association. In a study by Hoekstra et al., nonsense SDHA mutations were found at a frequency of $0.5 \%$ in a healthy population (40). Moreover, potentially (likely) pathogenic variants in $S D H x / M A X$ genes, such as loss of function variants, are registered in population databases including gnomAD. There may, therefore, be a risk of an incidental association between pituitary adenoma and the presence of $S D H x$ germline mutations. However, we did not identify any $S D H x / M A X$ (likely) pathogenic variants in a cohort of 239 patients who presented with hyperparathyroidism and who had no personal or family history of PPGL and PA (personal data). These data favor a non-random association between SDHx/MAX (likely) pathogenic variants and PAs.

It is also true that the involvement of $S D H x / M A X$ genes in PA tumorigenesis remains unclear. We have shown here that the age of onset of PA in patients with SDHx/MAX mutations is higher than that for other tumour suppressor genes and is equivalent to that of controls. The loss of expression of SDH within tumor tissue was not established in all patients, as was the case for cases 1 and 3 in our study. In published cases, among the 24 patients with PA and germline mutations in $S D H x$, SDHB IHC and LOH testing in tumor samples were done for ten cases, but a loss of staining/LOH was not observed in two of these, which does not support the hypothesis of Knudson's double hit in these cases. Nevertheless, the $S d h b+/-$ murine model is consistent with the involvement of SDHx mutation in pituitary tumorigenesis (5). At 12 months age, the $S d h b+/-$ mice developed a hyperplastic adenohypophysis, as is classically found in AIP-deficient mice (41) and in human PAs due to AIP, PRKAR1A mutations or Xq26 microduplication $(42,43,44)$. The adenohypophyseal cells of $S d h b+/-$ mice showed several intranuclear abnormalities and strong cytoplasmic and nuclear HIF- $1 \alpha$ staining consistent with the activation of the pseudohypoxia pathway in $S D H x$-mutated tumors (5, $9,45,46,47)$. Concerning $M A X$, there are no publications reporting $\mathrm{PA}$ associating germline $M A X$ mutation and negative MAX IHC and/or LOH or second somatic MAX mutation in PA tissue. Nevertheless in humans, data on the increased risk of PA in patients with $S D H x / M A X$ mutations is required to reach a conclusion on the need for pituitary gland monitoring in symptomatic and 
asymptomatic carriers of $S D H x / M A X$ mutations. Induced pluripotent stem cells (IPs) modified with the SDHx/MAX mutation and differentiated into pituitary cells may help to clarify the mechanisms of pituitary tumorigenesis in this syndrome.

On the other hand, SDHx/MAX genetic testing for patients with PA should be decided while also taking into account (1) the low penetrance of $S D H x$-related manifestations, (2) the possible anxiety generated by this information for the patient and their family, (3) the exposure to ionizing radiation related to lifetime monitoring, and (4) the cost of clinical follow-up.

Of the three variants identified in patients with isolated PA, two occurred in SDHA and one in SDHC. In the PPGL population, $S D H x$ germline mutations accounted for approximately $15 \%$ of all cases and for half of the familial cases. $S D H B$ and $S D H D$ mutations have been reported to be the most common, SDHA and SDHC mutations being less frequent (48). On a large series of SDHA-PPGL patients, the penetrance was calculated at $10 \%$ at 70 years of age (49), while Benn et al. and Maniam et al., using a Bayesian statistical approach, indicated an overall penetrance of $1.7 \%$ (95\% CI: $0.8-3.8 \%)$ and $0.1-4.9 \%$, respectively $(50,51)$. In the same study, Benn et al. calculated the SDHC penetrance at 8.3\% (95\% CI: $3.5-18.5 \%$ ) (50). Consequently, the absence of PPGL in our patients with $S D H A$ or $S D H C$ mutations, as well as in their families, is not unexpected since the penetrance of SDHA/SDHC-related PPGL is low and the age of disease onset is late. Indeed the age at PPGL diagnosis in SDHCand SDHA-related patients is usually 35-40 years. In our three patients, initial exploration did not reveal PPGL but a longer follow-up is required to conclude the absence of PPGL.

Therefore, until proven otherwise, these three patients are at risk of developing PPGL later and should benefit from long-term monitoring.

Indeed, data are lacking to determine if the increased risk of PPGL in families with SDHx mutations, without a family history of PPGL, is the same as that of a family with a history of PPGL, and if these patients require the same level of monitoring, especially for SDHA asymptomatic carriers. However, taking into account the current state of our knowledge, it seems obvious that the presence of $S D H x / M A X$ (likely) pathogenic variants in patients with isolated PAs justifies screening for PPGLs via careful clinical examination, full-body imaging, and the measurement of urinary catecholamine levels (40). Additionally, the monitoring data of patients with $S D H B$, $S D H C, S D H D$, and SDHAF2 mutations, as secondary findings in clinical exome and genome sequencing from the ACMG, should certainly provide some answers (52). In any case, patients with a PA must be carefully examined not only for their family history of PA, but also for a history of PPGL, particularly for those patients bearing macroprolactinomas. Taking into account the published data, in cases of a family history of PPGL, genetic screening for $S D H x / M A X$ is an absolute requirement for a family member bearing an isolated PA. For those patients with an isolated PA and any family history of PPGL, the benefit of $S D H x / M A X$ genetic testing remains to be assessed.

A rare condition that requires SDHX/MAX genetic testing in patients with PA appears to be the presence of intracytoplasmic vacuoles in tumoral cells, a particular histological phenotype that has been reported in $S D H x$ related PAs (7) (Supplementary Table 3). These vacuoles do not appear to be fragments of mitochondria or endoplasmic reticulum (6) and most likely represent autophagic bodies, due to pseudohypoxia $(47,53,54)$. In our patients, these vacuoles were not observed, but taking into account the literature, as in renal carcinoma (48), vacuolization of the cytoplasm should lead to SDHB (+/-SDHA) IHC and $S D H x$ genetic analysis being carried out.

In conclusion, we report for the first time $S D H x$ mutations in patients bearing PA without any family or personal history of PPGL. The prevalence rate of $1.1 \%$ is similar to that of MEN1 in this indication, raising the question of whether systematic genetic screening for $S D H x$ / $M A X$ is necessary for such patients. However, the question of incidental association remains unresolved. Data are lacking to determine the benefit of SDHx/MAX genetic testing of patients with isolated PA who have any family history of PPGL. Conversely, data on the increased risk of PA is needed to reach a conclusion on the pituitary gland monitoring in symptomatic and asymptomatic carriers of SDHx/MAX mutations. Meanwhile, we recommend a careful examination of patients with isolated PAs, not only on their family history of PAs but also on any history of PPGLs. Lastly, a family history of PPGL, as well as the presence of intracytoplasmic vacuoles in the PA, requires SDHx/MAX genetic testing for PA patients.

\section{Supplementary materials}

This is linked to the online version of the paper at https://doi.org/10.1530/ EJE-20-0054.

Declaration of interest

The authors declare that there is no conflict of interest that could be perceived as prejudicing the impartiality of this study. 


\section{Funding}

All phases of this study were supported by grants from the Institut National de lutte contre le Cancer (INCa) and the French Ministry of Health. The project leading to this publication received funding from the Excellence Initiative of Aix-Marseille University - A*Midex - a French 'Investissement d'Avenir'.

\section{Acknowledgements}

The authors thank all of the patients and their medical doctors and professors, namely Dr Amouroux, Pr Archambeaud, Dr Bahougne, Dr Barat, Dr Baudin, Dr Bennet, Dr Buffet, Pr Caron, Pr Chabre, Dr Chabrier, Pr Chevalier, Dr Coblence, Dr Coffin-Boutreux, Dr Cordroc's, Dr DalmThouvignon, Dr Decoudier, Dr Decoux-Poulot, Pr Delemer, Dr Demarquet, Dr Dequidt, Pr Drutel, Dr Esvant, Dr Fedala-Haddam, Dr Ferrière, Dr FlausFurmaniuk, Dr Frête, Dr Gall, Dr Gilly, Pr Goichot, Dr Guedj, Dr Guenego, Dr Haissaguerre, Dr Hawken, Dr Hieronimus, Dr Houcinat, Dr HoudonN'Guyen, Pr Kerlan, Dr Kalfallah, Pr Klein, Dr Le Marc Hadour, Dr Leheup, Dr Loddo, Dr Luca, Dr Luigi, Dr Ly, Dr Metz, Dr Morcrette, Dr Moutton, Dr Nivot-Adamiak, Dr Nizon, Dr Nunes, Dr Olivier, Dr Pascal, Dr Pienkowski, Dr Pihan Le Bars, Dr Plas, Dr Poirsier-Violle, Dr PorquetBordes, Dr Raingeard Dr Ramos Morange, Dr Raynaud-Ravni, Pr Reynaud, Dr Rochette, Dr Roudaut, Pr Sadoul, Dr Salle, Dr Schneebeli, Pr Sonnet, Pr Tabarin, Pr Teissier, Dr Telo, Dr Vautier, Dr Velayoudom-Cephise, Dr Verbeke, Dr Vermalle, Dr Vezzosi, Dr Vierge, Dr Vital, Dr Wagner, and Dr Zagdoun. The authors also thank Pr Dominique Figarella-Branger and Pr Henry Dufour.

\section{References}

1 Daly AF, Rixhon M, Adam C, Dempegioti A, Tichomirowa MA $\&$ Beckers A. High prevalence of pituitary adenomas: a crosssectional study in the province of Liège, Belgium. Journal of Clinical Endocrinology and Metabolism 200691 4769-4775. (https://doi. org/10.1210/jc.2006-1668)

2 Correa R, Salpea P \& Stratakis CA. Carney complex: an update. European Journal of Endocrinology 2015173 M85-M97. (https://doi. org/10.1530/EJE-15-0209)

3 Buffet A, Burnichon N, Favier J \& Gimenez-Roqueplo AP. An overview of 20 years of genetic studies in pheochromocytoma and paraganglioma. Best Practice and Research: Clinical Endocrinology and Metabolism 202034 101416. (https://doi.org/10.1016/j. beem.2020.101416)

4 Iversen K. Acromegaly associated with phaeochromocytoma. Acta Medica Scandinavica 1952142 1-5. (https://doi. org/10.1111/j.0954-6820.1952.tb13837.x)

5 Xekouki P, Szarek E, Bullova P, Giubellino A, Quezado M, Mastroyannis SA, Mastorakos P, Wassif CA, Raygada M, Rentia N et al. Pituitary adenoma with paraganglioma/pheochromocytoma (3PAs) and succinate dehydrogenase defects in humans and mice. Journal of Clinical Endocrinology and Metabolism 2015100 E710-E719. (https://doi.org/10.1210/jc.2014-4297)

6 Dénes J, Swords F, Rattenberry E, Stals K, Owens M, Cranston T, Xekouki P, Moran L, Kumar A, Wassif C et al. Heterogeneous genetic background of the association of pheochromocytoma/paraganglioma and pituitary adenoma: results from a large patient cohort. Journal of Clinical Endocrinology and Metabolism 2015100 E531-E541. (https://doi.org/10.1210/jc.2014-3399)

7 Denes J, Swords F, Xekouki P, Kumar AV, Maher ER, Wassif CA, Fersht N, Grieve J, Baldeweg SE, Stratakis CA et al. Familial pituitary adenoma and paraganglioma syndrome-a novel type of multiple endocrine neoplasia. Endocrine Reviews 201233 OR41-OR42. (https://doi.org/10.1093/edrv/33.supp.1)

8 Daly AF, Castermans E, Oudijk L, Guitelman MA, Beckers P, Potorac I, Neggers SJCMM, Sacre N, van der Lely AJ, Bours V et al.
Pheochromocytomas and pituitary adenomas in three patients with MAX exon deletions. Endocrine-Related Cancer 201825 L37-L42. (https://doi.org/10.1530/ERC-18-0065)

9 Xekouki P, Pacak K, Almeida M, Wassif CA, Rustin P, Nesterova M, De La Luz Sierra M, Matro J, Ball E, Azevedo M et al. Succinate dehydrogenase (SDH) D subunit (SDHD) inactivation in a growthhormone-producing pituitary tumor: a new association for SDH? Journal of Clinical Endocrinology and Metabolism 201297 E357-E366. (https://doi.org/10.1210/jc.2011-1179)

10 O’Toole SM, Dénes J, Robledo M, Stratakis CA \& Korbonits M. 15 Years of paraganglioma: the association of pituitary adenomas and phaeochromocytomas or paragangliomas. Endocrine-Related Cancer 201522 T105-T122. (https://doi.org/10.1530/ERC-15-0241)

11 den Dunnen JT, Dalgleish R, Maglott DR, Hart RK, Greenblatt MS, Mcgowan-Jordan J, Roux AF, Smith T, Antonarakis SE \& Taschner PEM. HGVS recommendations for the description of sequence variants: 2016 update. Human Mutation 201637 564-569. (https://doi.org/10.1002/humu.22981)

12 Richards S, Aziz N, Bale S, Bick D, Das S, Gastier-Foster J, Grody WW, Hegde M, Lyon E, Spector E et al. Standards and guidelines for the interpretation of sequence variants: a joint consensus recommendation of the American College of Medical Genetics and Genomics and the Association for Molecular Pathology Sue. Genetics in Medicine 201517 405-424. (https://doi.org/10.1038/gim.2015.30)

13 Ugalde C, Janssen RJRJ, van den Heuvel LP, Smeitink JAM \& Nijtmans LGJ. Differences in assembly or stability of complex I and other mitochondrial OXPHOS complexes in inherited complex I deficiency. Human Molecular Genetics 200413 659-667. (https://doi. org/10.1093/hmg/ddh071)

14 Romanet P, Mohamed A, Giraud S, Odou MF, North MO, Pertuit M, Pasmant E, Coppin L, Guien C, Calender A et al. UMD-MEN1 database: an overview of the 370 MEN1 variants present in 1676 patients from the French population. Journal of Clinical Endocrinology and Metabolism 2019104 753-764. (https://doi.org/10.1210/jc.201801170)

15 Cuny T, Mac TT, Romanet P, Dufour H, Morange I, Albarel F, Lagarde A, Castinetti F, Graillon T, North MO et al. Acromegaly in Carney complex. Pituitary 201922 456-466. (https://doi. org/10.1007/s11102-019-00974-8)

16 Alrezk R, Hannah-Shmouni F \& Stratakis CA. MEN4 and CDKN1B mutations: the latest of the MEN syndromes. Endocrine-Related Cancer 201724 T195-T208. (https://doi.org/10.1530/ERC-17-0243)

17 Frederiksen A, Rossing M, Hermann P, Ejersted C, Thakker RV \& Frost M. Clinical features of multiple endocrine neoplasia type 4: novel pathogenic variant and review of published cases. Journal of Clinical Endocrinology and Metabolism 2019104 3637-3646. (https:// doi.org/10.1210/jc.2019-00082)

18 Trouillas J, Roy P, Sturm N, Dantony E, Cortet-Rudelli C, Viennet G, Bonneville JF, Assaker R, Auger C, Brue T et al. A new prognostic clinicopathological classification of pituitary adenomas: a multicentric case-control study of 410 patients with 8 years postoperative follow-up. Acta Neuropathologica 2013126 123-135. (https://doi.org/10.1007/s00401-013-1084-y)

19 Niemann S, Müller U, Engelhardt D \& Lohse P. Autosomal dominant malignant and catecholamine-producing paraganglioma caused by a splice donor site mutation in SDHC. Human Genetics $2003 \mathbf{1 1 3}$ 92-94. (https://doi.org/10.1007/s00439-003-0938-0).

20 Casey RT, Ascher DB, Rattenberry E, Izatt L, Andrews KA, Simpson HL, Challis B, Park SM, Bulusu VR, Lalloo F et al. SDHA related tumorigenesis: a new case series and literature review for variant interpretation and pathogenicity. Molecular Genetics and Genomic Medicine 20175 237-250. (https://doi.org/10.1002/ mgg3.279)

21 Roszko KL, Blouch E, Blake M, Powers JF, Tischler AS, Hodin R, Sadow P \& Lawson EA. Case report of a prolactinoma in a patient with a novel MAX mutation and bilateral pheochromocytomas. 
Journal of the Endocrine Society 20171 1401-1407. (https://doi. org/10.1210/js.2017-00135)

22 López-Jiménez E, De JM, Kusak EM, Landa I, Leskelä S, MonteroConde C, Leandro-García LJ, Vallejo LA, Madrigal B, RodríguezAntona C et al. SDHC mutation in an elderly patient without familial antecedents. Clinical Endocrinology 200869 906-910. (https://doi. org/10.1111/j.1365-2265.2008.03368.x)

23 Papathomas TG, Gaal J, Corssmit EPM, Oudijk L, Korpershoek E, Heimdal K, Bayley JP, Morreau H, Van Dooren M, Papaspyrou K et al. Non-pheochromocytoma (PCC)/paraganglioma (PGL) tumors in patients with succinate dehydrogenase-related PCC-PGL syndromes: a clinicopathological and molecular analysis. European Journal of Endocrinology 2014170 1-12. (https://doi.org/10.1530/EJE-13-0623)

24 Varsavsky M, Sebastián-Ochoa A \& Torres Vela E. Coexistence of a pituitary macroadenoma and multicentric paraganglioma: a strange coincidence. Endocrinologia y Nutricion: Organo de la Sociedad Espanola de Endocrinologia y Nutricion 201360 154-156. (https://doi. org/10.1016/j.endonu.2012.02.009)

25 Niemeijer ND, Papathomas TG, Korpershoek E, De Krijger RR, Oudijk L, Morreau H, Bayley JP, Hes FJ, Jansen JC, Dinjens WNM et al. Succinate dehydrogenase (SDH)-deficient pancreatic neuroendocrine tumor expands the SDH-related tumor spectrum. Journal of Clinical Endocrinology and Metabolism 2015100 E1386-E1393. (https://doi.org/10.1210/jc.2015-2689)

26 Gorospe L, Cabañero-Sánchez A, Muñoz-Molina GM, PaciosBlanco RE, Ureña Vacas A \& García-Santana E. An unusual case of mediastinal paraganglioma and pituitary adenoma. Surgery 2017162 1338-1339. (https://doi.org/10.1016/j.surg.2017.03.003)

27 Lemelin A, Lapoirie M, Abeillon J, Lasolle H, Giraud S, Philouze P, Ceruse P, Raverot G, Vighetto A \& Borson-Chazot F. Pheochromocytoma, paragangliomas, and pituitary adenoma: an unusual association in a patient with an SDHD mutation. Case report. Medicine 201998 e16594. (https://doi.org/10.1097/ MD.0000000000016594)

28 Guerrero Pérez F, Lisbona Gil A, Robledo M, Iglesias P \& Villabona Artero C. Adenoma hipofisario asociado a feocromocitoma/ paraganglioma: una nueva forma de neoplasia endocrina múltiple. Endocrinologia y Nutricion 201663 506-508. (https://doi. org/10.1016/j.endonu.2016.07.007)

29 Guerrero-Pérez F, Fajardo C, Torres Vela E, Giménez-Palop O, Lisbona Gil A, Martín T, González N, Díez JJ, Iglesias P, Robledo M et al. 3P association (3PAs): pituitary adenoma and pheochromocytoma/ paraganglioma. A heterogeneous clinical syndrome associated with different gene mutations. European Journal of Internal Medicine 2019 69 14-19. (https://doi.org/10.1016/j.ejim.2019.08.005)

30 Dwight T, Mann K, Benn DE, Robinson BG, McKelvie P, Gill AJ, Winship I \& Clifton-Bligh RJ. Familial SDHA mutation associated with pituitary adenoma and pheochromocytoma/paraganglioma. Journal of Clinical Endocrinology and Metabolism 201398 E1103-E1108. (https://doi.org/10.1210/jc.2013-1400)

31 Maher M, Roncaroli F, Mendoza N, Meeran K, Canham N, KosickaSlawinska M, Bernhard B, Collier D, Drummond J, Skordilis K et al. A patient with a germline SDHB mutation presenting with an isolated pituitary macroprolactinoma. Endocrinology, Diabetes and Metabolism Case Reports 20182018 18-0078. (https://doi.org/10.1530/EDM-180078)

32 Benn DE, Gimenez-Roqueplo AP, Reilly JR, Bertherat J, Burgess J, Byth K, Croxson M, Dahia PLM, Elston M, Gimm O et al. Clinical presentation and penetrance of pheochromocytoma/paraganglioma syndromes. Journal of Clinical Endocrinology and Metabolism 200691 827-836. (https://doi.org/10.1210/jc.2005-1862).

33 Caimari F \& Korbonits M. Novel genetic causes of pituitary adenomas. Clinical Cancer Research 201622 5030-5042. (https://doi. org/10.1158/1078-0432.CCR-16-0452)

34 Cazabat L, Libè R, Perlemoine K, René-Corail F, Burnichon N, Gimenez-Roqueplo AP, Dupasquier-Fediaevsky L, Bertagna X,
Clauser E, Chanson P et al. Germline inactivating mutations of the aryl hydrocarbon receptor-interacting protein gene in a large cohort of sporadic acromegaly: mutations are found in a subset of young patients with macroadenomas. European Journal of Endocrinology 2007 157 1-8. (https://doi.org/10.1530/EJE-07-0181)

35 Occhi G, Trivellin G, Ceccato F, De Lazzari P, Giorgi G, Demattè S, Grimaldi F, Castello R, Davì MV, Arnaldi G et al. Prevalence of AIP mutations in a large series of sporadic Italian acromegalic patients and evaluation of CDKN1B status in acromegalic patients with multiple endocrine neoplasia. European Journal of Endocrinology 2010 163 369-376. (https://doi.org/10.1530/EJE-10-0327)

36 Ferraù F, Romeo PD, Puglisi S, Ragonese M, Torre ML, Scaroni C, Occhi G, De Menis E, Arnaldi G, Trimarchi F et al. Analysis of GPR101 and AIP genes mutations in acromegaly: a multicentric study. Endocrine 201654 762-767. (https://doi.org/10.1007/s12020016-0862-4)

37 Hernández-Ramírez LC, Gabrovska P, Dénes J, Stals K, Trivellin G, Tilley D, Ferraù F, Evanson J, Ellard S, Grossman AB et al. Landscape of familial isolated and young-onset pituitary adenomas: prospective diagnosis in AIP mutation carriers. Journal of Clinical Endocrinology and Metabolism 2015100 E1242-E1254. (https://doi.org/10.1210/ jc. 2015-1869)

38 Cuny T, Pertuit M, Sahnoun-Fathallah M, Daly A, Occhi G, Odou MF, Tabarin A, Nunes ML, Delemer B, Rohmer V et al. Genetic analysis in young patients with sporadic pituitary macroadenomas: besides AIP don't forget MEN1 genetic analysis. European Journal of Endocrinology 2013168 533-541. (https://doi.org/10.1530/EJE-12-0763)

39 Tichomirowa MA, Barlier A, Daly AF, Jaffrain-Rea ML, Ronchi C, Yaneva M, Urban JD, Petrossians P, Elenkova A, Tabarin A et al. High prevalence of AIP gene mutations following focused screening in young patients with sporadic pituitary macroadenomas. European Journal of Endocrinology 2011165 509-515. (https://doi.org/10.1530/ EJE-11-0304)

40 Hoekstra AS \& Bayley JP. The role of complex II in disease. Biochimica et Biophysica Acta 20131827 543-551. (https://doi.org/10.1016/j. bbabio.2012.11.005)

41 Lecoq AL, Zizzari P, Hage M, Decourtye L, Adam C, Viengchareun S, Veldhuis JD, Geoffroy V, Lombès M, Tolle V et al. Mild pituitary phenotype in 3- and 12-month-old Aip-deficient male mice. Journal of Endocrinology 2016231 59-69. (https://doi.org/10.1530/JOE-160190)

42 Villa C, Lagonigro MS, Magri F, Koziak M, Jaffrain-Rea ML, Brauner R, Bouligand J, Junier MP, Di Rocco F, Sainte-Rose C et al. Hyperplasiaadenoma sequence in pituitary tumorigenesis related to aryl hydrocarbon receptor interacting protein gene mutation. EndocrineRelated Cancer 201118 347-356. (https://doi.org/10.1530/ERC-110059)

43 Stergiopoulos SG, Abu-Asab MS, Tsokos M \& Stratakis CA. Pituitary pathology in Carney complex patients. Pituitary 2004 73-82. (https://doi.org/10.1007/s11102-005-5348-y)

44 Trivellin G, Daly AF, Faucz FR, Yuan B, Rostomyan L, Larco DO, Schernthaner-Reiter MH, Szarek E, Leal LF, Caberg JH et al. Gigantism and acromegaly due to Xq26 microduplications and GPR101 mutation. New England Journal of Medicine 2014371 2363-2374. (https://doi.org/10.1056/NEJMoa1408028)

45 Xekouki P, Brennand A, Whitelaw B, Pacak K \& Stratakis CA. The 3PAs: an update on the Association of Pheochromocytomas, Paragangliomas, and Pituitary Tumors. Hormone and Metabolic Research 201951 419-436. (https://doi.org/10.1055/a-0661-0341)

46 Bardella C, Pollard PJ \& Tomlinson I. SDH mutations in cancer. Biochimica et Biophysica Acta 20111807 1432-1443. (https://doi. org/10.1016/j.bbabio.2011.07.003)

47 Xekouki P \& Stratakis CA. Succinate dehydrogenase (SDHx) mutations in pituitary tumors: could this be a new role for mitochondrial complex II and/or Krebs cycle defects? Endocrine-Related Cancer 2012 19 C33-C40. (https://doi.org/10.1530/ERC-12-0118) 
48 Gill AJ. Succinate dehydrogenase (SDH)-deficient neoplasia. Histopathology 201872 106-116. (https://doi.org/10.1111/ his.13277)

49 Van Der Tuin K, Mensenkamp AR, Tops CMJ, Corssmit EPM, Dinjens WN, Van De Horst-Schrivers AN, Jansen JC, Jong MM De, Kunst HPM, Kusters B et al. Clinical aspects of SDHA-related pheochromocytoma and paraganglioma: a nationwide study. Journal of Clinical Endocrinology and Metabolism 2018103 438-445. (https:// doi.org/10.1210/jc.2017-01762)

50 Benn DE, Zhu Y, Andrews KA, Wilding M, Duncan EL, Dwight T, Tothill RW, Burgess J, Crook A, Gill AJ et al. Bayesian approach to determining penetrance of pathogenic SDH variants. Journal of Medical Genetics 201855 729-734. (https://doi.org/10.1136/ jmedgenet-2018-105427)

51 Maniam P, Zhou K, Lonergan M, Berg JN, Goudie DR \& Newey PJ. Pathogenicity and penetrance of germline SDHA variants in pheochromocytoma and paraganglioma (PPGL). Journal of the Endocrine Society 20182 806-816. (https://doi.org/10.1210/js.201800120)

52 Kalia SS, Adelman K, Bale SJ, Chung WK, Eng C, Evans JP, Herman GE, Hufnagel SB, Klein TE, Korf BR et al. Recommendations for reporting of secondary findings in clinical exome and genome sequencing, 2016 update (ACMG SF v2.0): a policy statement of the American College of Medical Genetics and Genomics. Genetics in Medicine 201719 249-255. (https://doi.org/10.1038/gim.2016.190)

53 Ishikawa T, Miyaishi S, Tachibana T, Ishizu H, Zhu BL \& Maeda H. Fatal hypothermia related vacuolation of hormone-producing cells in the anterior pituitary. Legal Medicine 20046 157-163. (https://doi. org/10.1016/j.legalmed.2004.05.004)

54 Doberentz E \& Madea B. Microscopic examination of pituitary glands in cases of fatal accidental hypothermia. Forensic Sciences Research 20172 132-138. (https://doi.org/10.1080/20961790.2017.1330804)

Received 17 January 2020

Revised version received 12 June 2020

Accepted 2 July 2020 